\title{
Prevalence of Color Vision Deficiency among Medical Students
}

Muhammad Zunair Aziz¹, Muhammad Moeez Uddin¹, Umar Farooque², Rizwan Farooque ${ }^{3}$, Sundas Karimi ${ }^{4}$

1. Ophthalmology, Prevention of Blindness (POB) Trust Charitable Eye Hospital, Karachi, Pakistan

2. Neurology, Dow University of Health Sciences, Karachi, Pakistan

3. Internal Medicine, Jinnah Sindh Medical University, Karachi, Pakistan

4. Orthopedics Surgery, Dow University Hospital, Karachi, Pakistan

Corresponding author:

Umar Farooque, Neurology, Dow University of Health Sciences, Karachi, Pakistan

E-mail address: umarfarooque65@gmail.com 


\section{Abstract \\ Introduction}

Color vision deficiency (CVD) constitutes one of the frequently observed eye disorders in all human populations. Color is a prominent sign utilized in the medical profession to study and identify histopathological specimens, lab instruments, and patient examination. Color deficiency affects the medical skills of students resulting in poor clinical examination and color appreciation. There is no effective screening of CVD at any level of the medical profession. Hence, this study was aimed to determine the prevalence of CVD among medical students.

\section{Materials and methods}

This was a cross-sectional study conducted from September 2019 to February 2020 over a period of six months in Karachi, Pakistan. All medical students aged 18-21 years of either gender enrolled in the first and second years of medical college were included in this study. The examination was performed during daylight. Ishihara plates were placed at a distance of $75 \mathrm{~cm}$ from the subject and tilted so that the plane of the paper lies perpendicular to the line of vision. Students were given five seconds to read the plate and one examiner was instructed to mark the checklist. A score of less than 12 out of $14 \mathrm{red} / \mathrm{green}$ test plates (not including the demonstration plate) was considered as a CVD. All statistical analysis was performed using Statistical Package for Social Sciences version 20.0 (Armonk, NY: IBM Corp).

\section{Results}

The mean age of the medical students was $19.61 \pm 1.22$ years. There were $(n=123)$ $53.0 \%$ females and $(n=111) 47.0 \%$ males. Most of the medical students $(n=131,56.0 \%)$ belonged to the upper-middle-class socioeconomic group. CVD was observed in $(n=13)$ $6.0 \%$ of medical students. Age $(p=0.001)$ and socioeconomic status $(p=0.001)$ were the only demographic factors significantly associated with color deficiency.

\section{Conclusions}

Color deficiency, although an unnoticed concern, is fairly common among medical students. Medical students must be screened for CVD as this will enable them to be aware of their limitations in their future observational skills as a doctor and devise ways of overcoming them in clinical practice.

\section{Keywords}

color vision deficiency, medical students, ishihara plates, humans, incidence, prevalence, frequency 


\section{Introduction}

Color vision deficiency (CVD), also known as color blindness, constitutes one of the frequently reported eye disorders among all human populations. The ability of the eye to see 150 different colors distinguishes humans from other species [1]. This disorder can be further categorized into congenital and acquired. The congenital form of this disorder involves sex-linked recessive traits with genes located on the $\mathrm{X}$ chromosome within the Xq28 band. A variable prevalence of CVD has been previously reported with $8.7 \%$ among Jordanian males and $0.3 \%$ among females [2]. Another study reported a color blindness prevalence rate of $8.0 \%$ among British male physicians [3].

Campbell et al. in their study demonstrated that physicians suffering from color blindness were unable to identify and outline clinical features in 10 photographs out of which eight were vomit and stool (of which six showed fresh blood), one skin rash, and one marked the position of bacilli in sputum stained by Ziehl- Neelson method, whereas physicians with normal color vision did it easily [4].

The differential colors provided by staining techniques play a prominent role in the examination of histopathologic and histologic microscopic sections. For instance, hematoxylin and eosin dyes are utilized to delineate normal tissue components and for the identification of pathologic alterations in test components. This dependence upon differentiation of colors for proper histologic examination poses a significant difficulty for several medical students enrolled in study courses that involve the identification of histological slides given the prevalence of color blindness in the general population [5].

Previously, medical students suffering from this disorder were recommended to use color transparency overlays or tinted contact lenses to filter out the problematic color. However recently, computer monitors adjusted to grayscale are being increasingly used in addition to grayscale versions of color photomicrographs for laboratory examination. Grayscale images are beneficial as these emphasize the contrast between tissues and the color of the tissues enabling color deficient students to learn histological architecture by focusing on cell and tissue structure rather than on color variation. Rubin et al. further stated grayscale photomicrographs to be beneficial for students with normal (trichromatic) color vision in addition to those with color deficiency as these encourage students to focus on structural characteristics of cells and tissues that might otherwise be overshadowed by stain colors [5].

In a study, after careful screening, it was noted that among medical students, seven $(5.8 \%)$ had color deficiency [6]. In a local study, no significant difference was observed 
among male engineering versus medical students in the CVD rate $(2.7 \%$ vs $4.4 \%$, $\mathrm{p}=0.125$ ) [7]. The information is limited on the prevalence of CVD among medical students. Therefore, the primary objective of this study was to determine the incidence of CVD among medical students. A secondary aim was to determine the impact of socio-demographic factors on the incidence of color deficiency.

Materials \& Methods

\section{Study setting and design}

This cross-sectional study was conducted over a period of six months between September 2019 and February 2020 in Karachi, Pakistan. The ethics committee of Prevention of Blindness (POB) Trust Charitable Eye Hospital, Karachi, Pakistan approved this study with approval number of 26739/23.

\section{Sample size, inclusion/exclusion criteria}

A sample size of 234 medical students was calculated using Openepi (Open Source Epidemiologic Statistics for Public Health) at an anticipated CVD frequency of $5.8 \%$ at a confidence interval of $95 \%$ and a $5 \%$ margin of error [6]. All medical students aged $18-$ 21 years of either gender (i.e. male or female) enrolled in first and second years of medical college were included in this study. All subjects gave their informed consent for inclusion before they participated in the study. We excluded all medical students with a known ocular abnormality, eye infections, and known color blindness. The study was conducted in accordance with the Declaration of Helsinki

\section{Sampling technique and data collection}

A simple random sampling technique was employed to collect data. A list of medical students enrolled in first and second years was obtained from the college administration and the registration numbers were entered into the software that enabled the random selection of medical students. The purpose and procedure of the study were explained to all medical students following which both verbal and written informed consent were taken. The researcher examined the students in daylight between $11.00 \mathrm{am}$ to $1.00 \mathrm{pm}$. Ishihara plates were placed at a distance of $75 \mathrm{~cm}$ from the subject and tilted so that the plane of the paper lies perpendicular to the line of vision. Students were given five seconds to read the plate and an examiner was asked to mark the checklist. A score of $<12$ out of $14 \mathrm{red} / \mathrm{green}$ test plates (not including the demonstration plate) was considered as a CVD and a score of $\geq 12$ indicated normal vision. Additional 
demographic variables such as age, gender, and socioeconomic status of the students were also entered into the pre-defined proforma by the investigators.

\section{Statistical analysis}

Data were entered and analyzed using Statistical Package for Social Sciences version 20.0 (Armonk, NY: IBM Corp). Continuous variables such as age, weight, height, and body mass index (BMI) of the students were presented as mean and standard deviation. Categorical variables such as gender, socioeconomic status, and CVD rate were presented as frequencies and percentages. Stratification of age, gender, BMI, and socioeconomic status was done to control effect modifiers. Chi-square test was applied post-stratification and $p$-value $\leq 0.05$ was taken as statistically significant.

\section{Results}

The mean age of the medical students was $19.61 \pm 1.22$ years. Most of the medical students $(n=152,65.0 \%)$ were $\leq 20$ years of age, as shown in Figure 1.

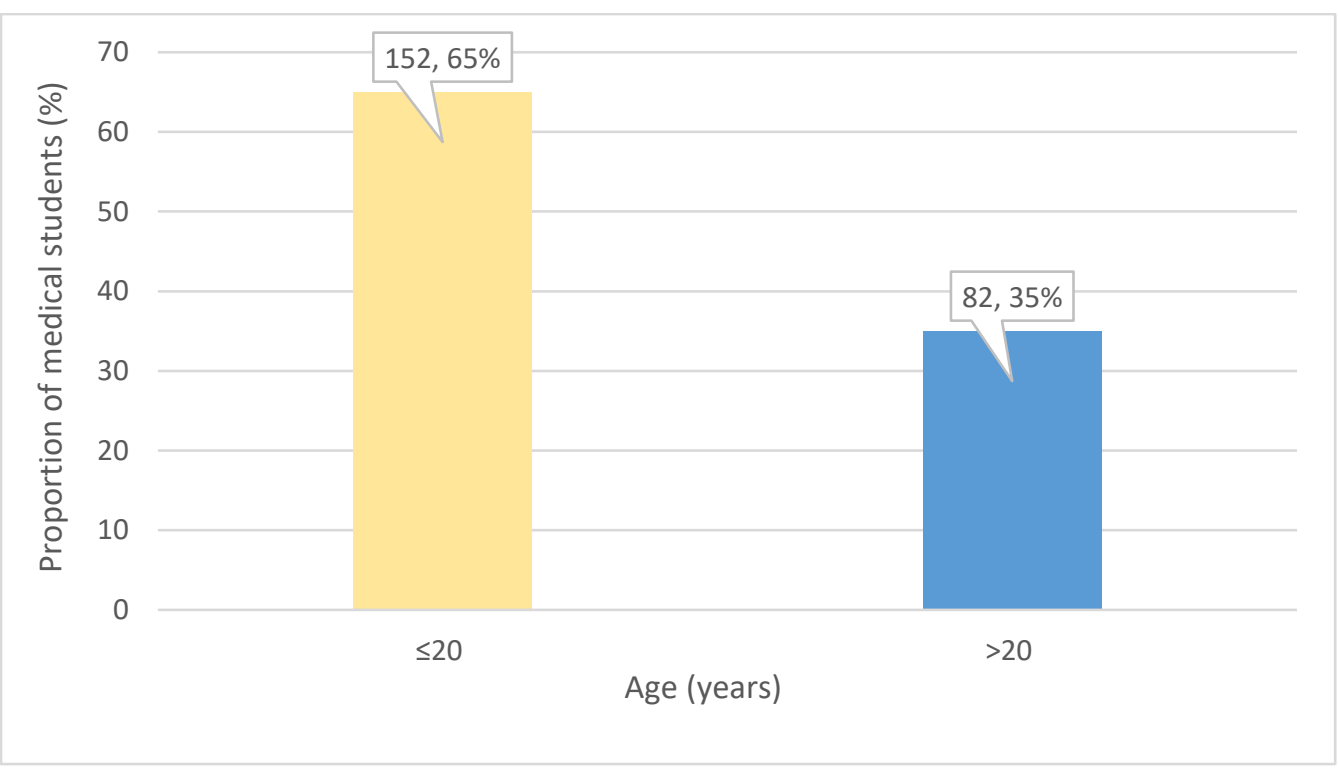

Figure 1: Distribution of participants according to age

More than half ( $n=123,53.0 \%)$ of medical students were females, and greater than twofifths $(n=111,47.0 \%)$ were males, as shown in Figure 2. 


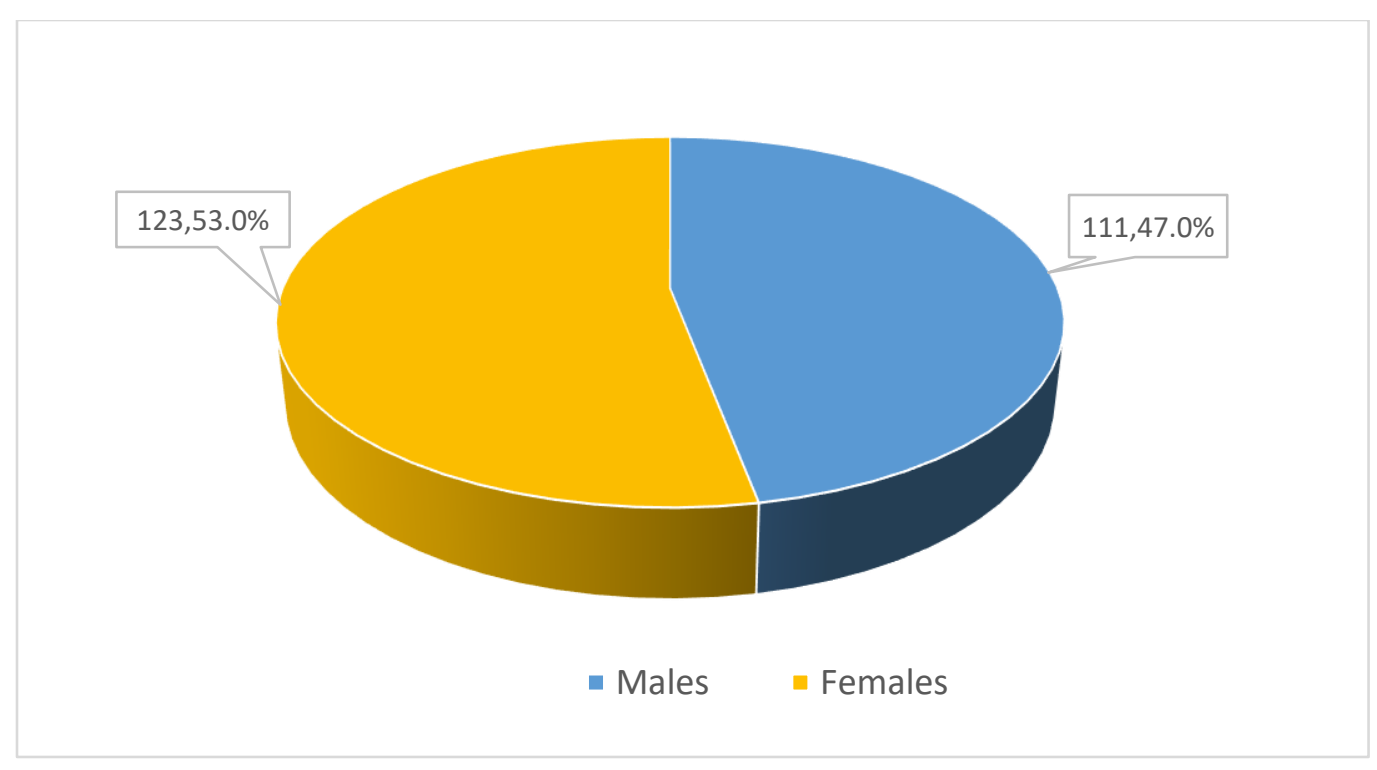

Figure 2: Distribution of participants according to gender

The mean weight of the medical students was $60.01 \pm 4.91 \mathrm{~kg}$. Three-fifths $(n=140$, $60.0 \%$ ) of medical students weighed $\leq 60 \mathrm{~kg}$, as shown in Figure 3.

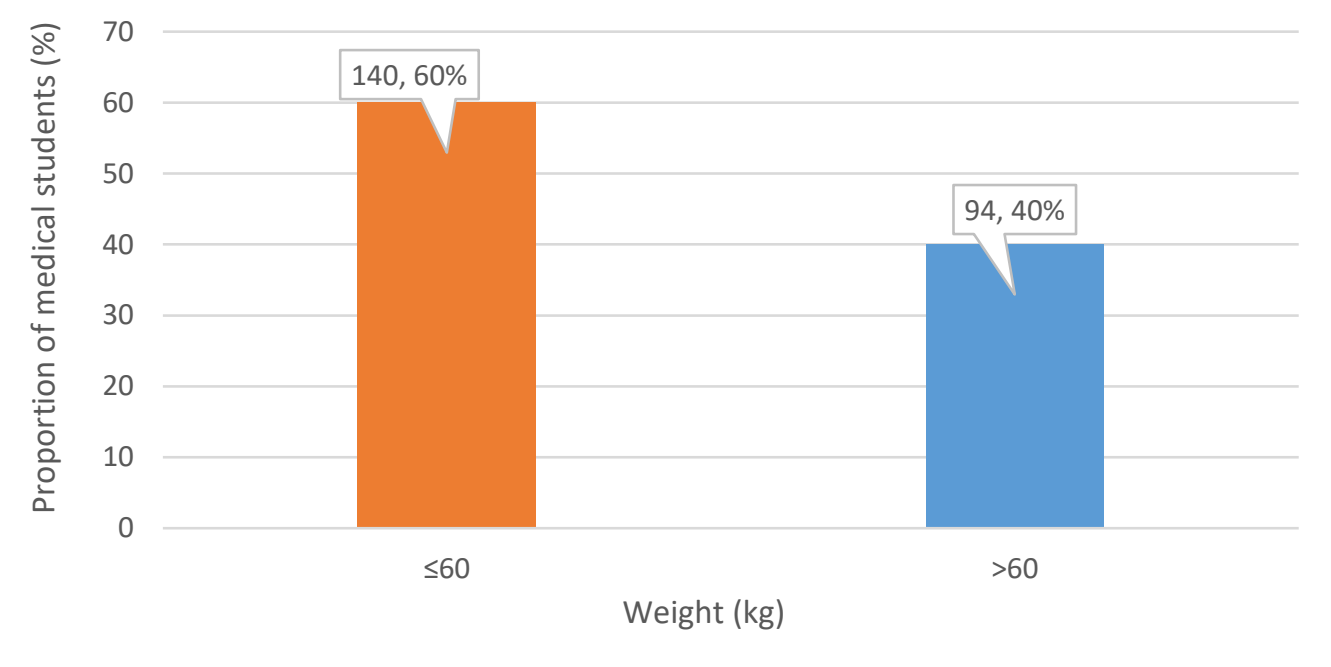

Figure 3: Distribution of participants according to weight

The mean height of the medical students was $1.55 \pm 0.06 \mathrm{~m}$. Most of the medical students $(n=140,60.0 \%)$ were $\leq 1.6 \mathrm{~m}$ tall, as shown in Figure 4 . 


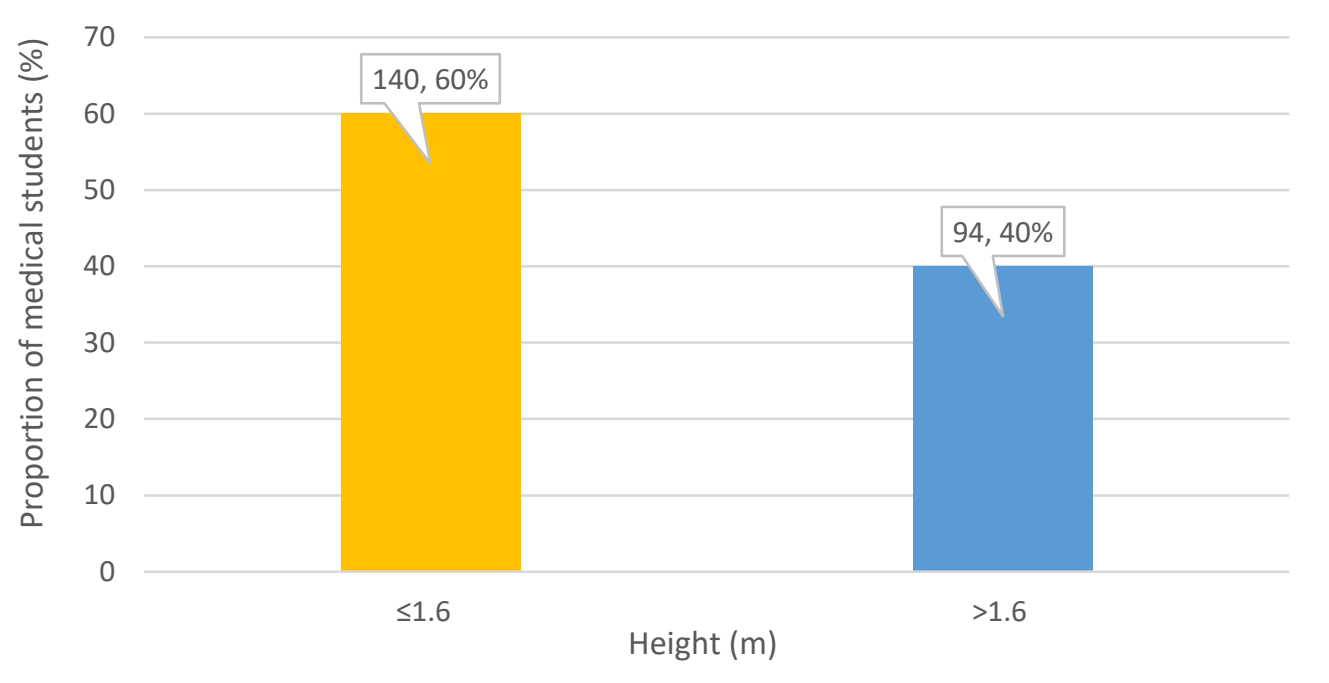

Figure 4: Distribution of participants according to height

The mean BMl of the medical students was $23.69 \pm 4.11 \mathrm{~kg} / \mathrm{m}^{2}$. BMl $\leq 24 \mathrm{~kg} / \mathrm{m}^{2}$ was observed in nearly three-quarters ( $\mathrm{n}=174,74.0 \%)$ of medical students, as shown in Figure 5.

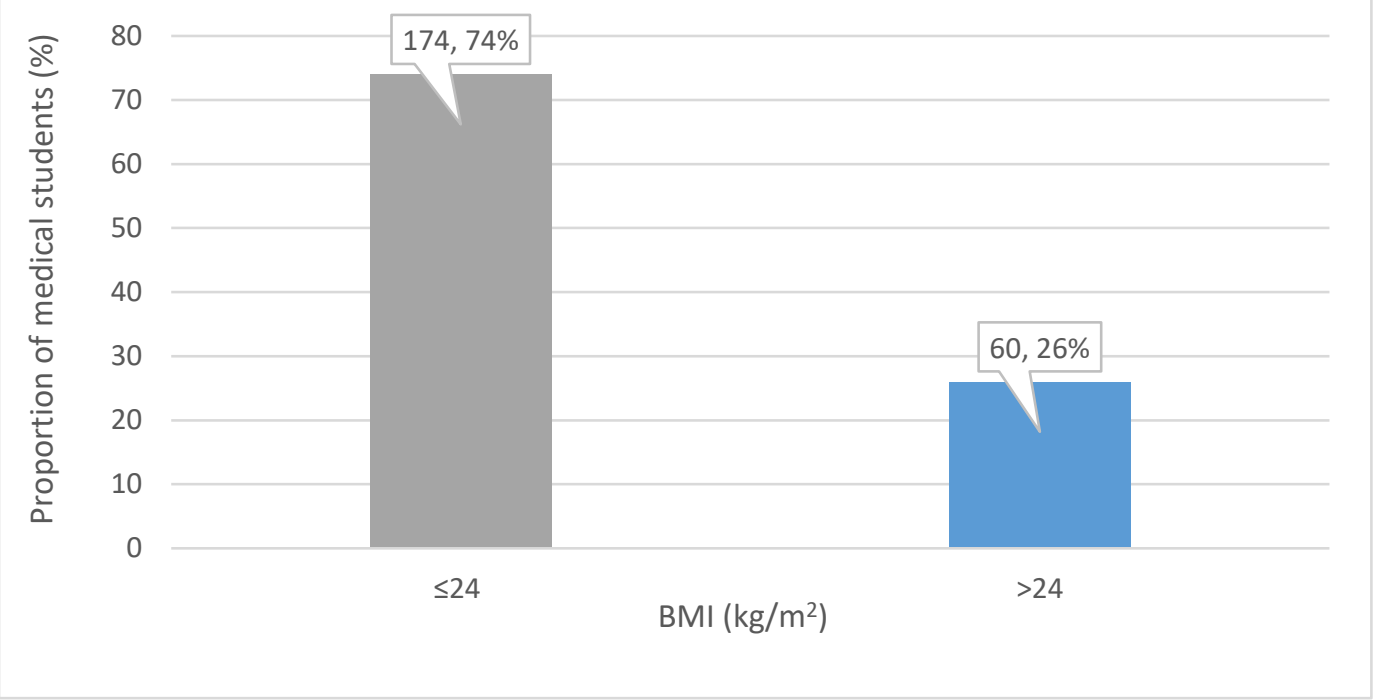

Figure 5: Distribution of participants according to BMI

BMI- body mass index 
Most of the medical students $(n=131,56.0 \%)$ belonged to the upper-middle-class socioeconomic group, as shown in Figure 6.

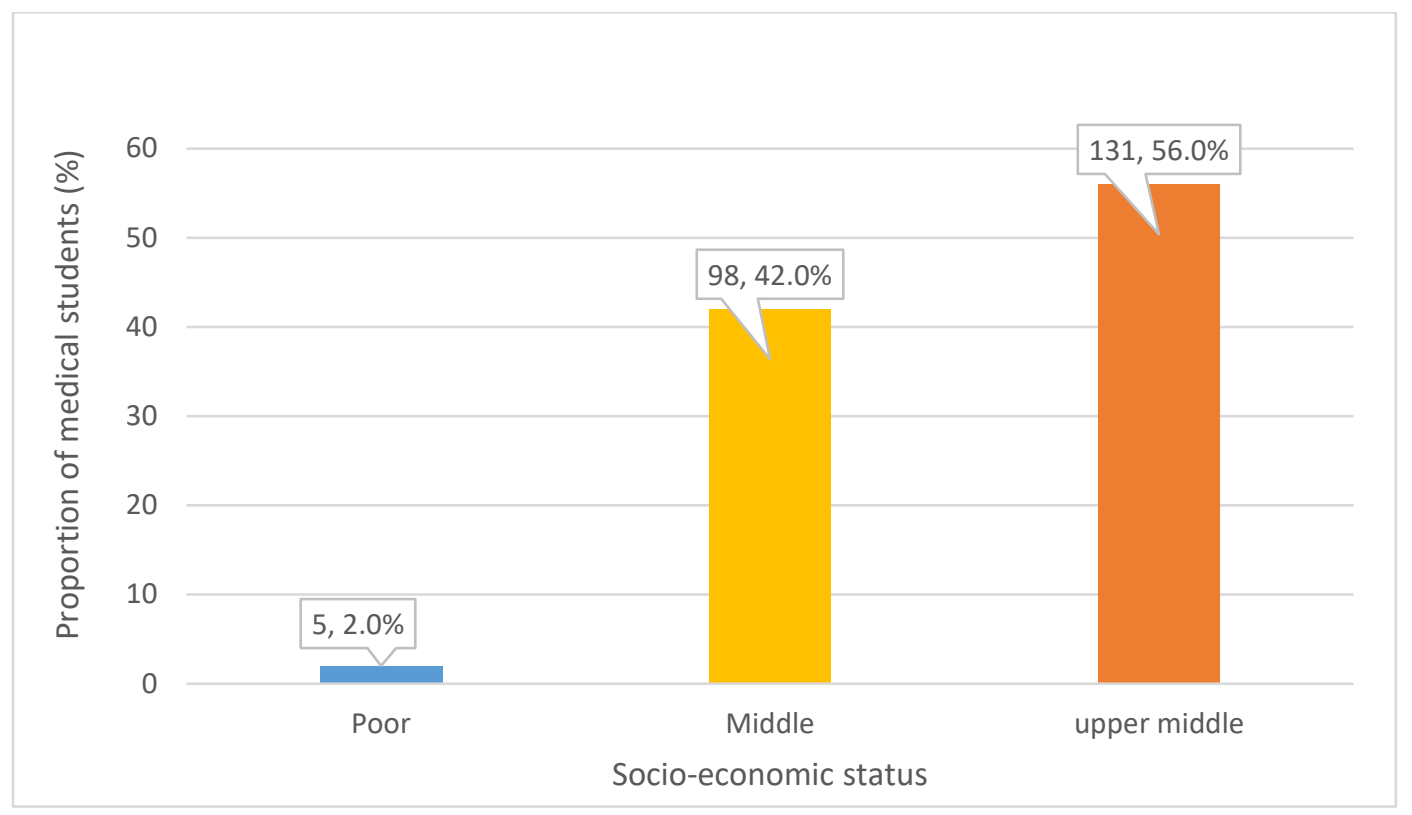

Figure 6: Distribution of participants according to socioeconomic status

Color vision deficiency was observed in $(n=13) 6.0 \%$ of medical students, as shown in Figure 7.

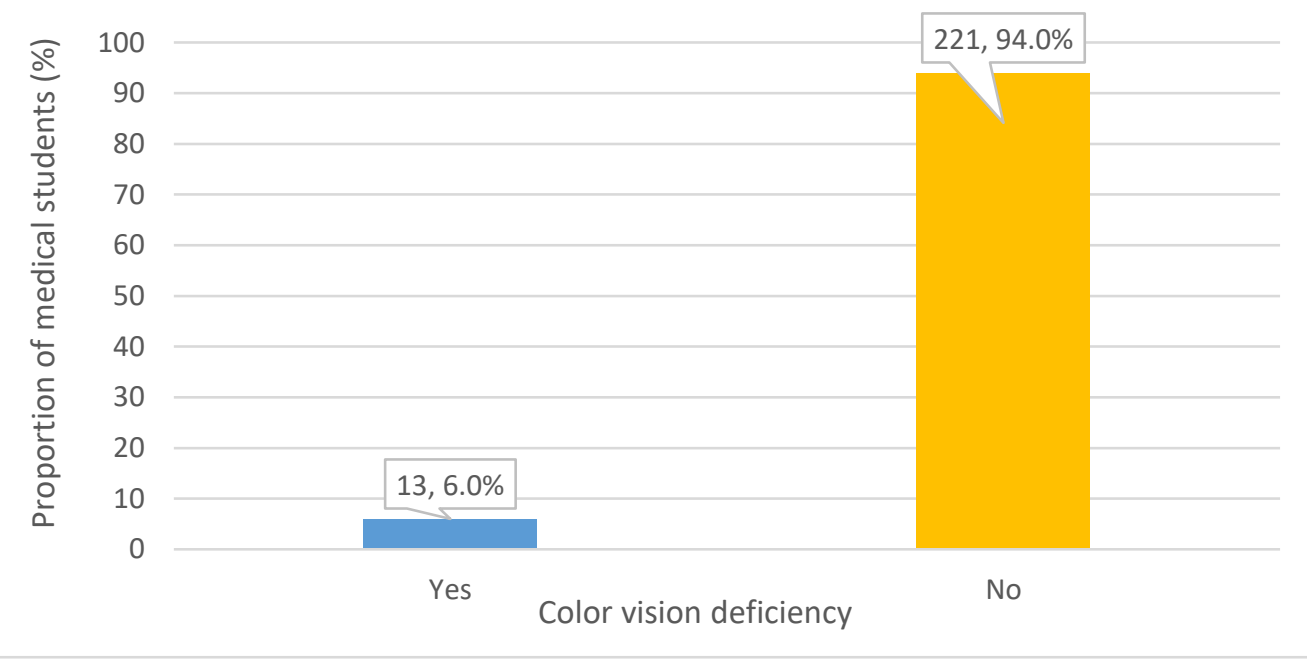

Figure 7: Prevalence of color vision deficiency among the participants

Stratification of age, gender, BMI, and socioeconomic status was performed to observe the impact of these factors on the prevalence of CVD. Age and socioeconomic status 
were observed to be significantly associated with the incidence of color deficiency. A higher proportion ( $n=10,76.9 \%$ ) of color vision weak medical students were aged $>20$ years $(p=0.001)$. Moreover, equal proportions $(n=4,30.8 \%)$ of color deficient medical students belonged to the middle and upper-middle-class socioeconomic groups $(p=0.001)$. These findings are shown in Table 1.

\begin{tabular}{|c|c|c|c|c|}
\hline \multirow{2}{*}{\multicolumn{2}{|c|}{ Variables }} & \multirow{2}{*}{\multicolumn{2}{|c|}{ Presence of color deficiency }} & \multirow[t]{3}{*}{ P-value } \\
\hline & & & & \\
\hline \multirow[t]{2}{*}{ Gender } & Male & $\begin{array}{l}\text { Yes }(n=13 ; \\
6.0 \%) \\
3(23.1 \%)\end{array}$ & $\begin{array}{l}\text { No }(221 ; 94.0 \%) \\
108(48.9 \%)\end{array}$ & \\
\hline & Female & $10(76.9 \%)$ & $113(51.1 \%)$ & 0.070 \\
\hline \multirow[t]{2}{*}{ Age (years) } & $\leq 20$ & $3(23.1 \%)$ & $149(67.4 \%)$ & \multirow[t]{2}{*}{$0.001^{*}$} \\
\hline & $>20$ & $10(76.9 \%)$ & $72(32.6 \%)$ & \\
\hline \multirow{2}{*}{ BMI $\left(\mathrm{kg} / \mathrm{m}^{2}\right)$} & $\leq 24$ & $10(76.9 \%)$ & $164(74.2 \%)$ & \multirow[t]{2}{*}{0.828} \\
\hline & $>24$ & $3(23.1 \%)$ & $57(25.8 \%)$ & \\
\hline \multirow{3}{*}{$\begin{array}{l}\text { Socioeconomic } \\
\text { groups }\end{array}$} & Poor & $5(38.5 \%)$ & $0(0 \%)$ & \multirow[t]{3}{*}{$0.001^{*}$} \\
\hline & Middle & $4(30.8 \%)$ & $94(42.5 \%)$ & \\
\hline & Upper middle & $4(30.8 \%)$ & $127(57.5 \%)$ & \\
\hline
\end{tabular}

Table 1: Association of socio-demographic factors with the presence of color vision deficiency

BMI- body mass index

\section{Discussion}

The findings of this observational study demonstrated that color deficiency is not very rare among students enrolled in the medical profession, however it is as an unnoticed problem. Previous literature suggests health-care professionals suffering from color blindness to encounter a wide array of inconveniences in their professional, clinical, and laboratory skills. These difficulties include recognition of widespread body color changes such as cyanosis, rashes, jaundice, and pallor amongst others. Additional barriers include difficulty in recognition of blood and urine colorimetric tests-strips, and the presence of blood or bile in urine, sputum, vomit, and feces. These also comprise failure to study colorful charts and slides, mouth and throat clinical examination, titration endpoints as well as tissue identification while performing surgical procedures [8]. In case the physician fails to identify certain clinical symptoms due to color deficiency, the patient's medical issue may remain undetected leading to a worse prognosis when it could be timely prevented and treated. Spalding et al. in their study further stated that doctors and nurses with moderate to severe CVD performed worse in certain medical procedures compared to those with normal color vision [3]. 
This study reported a CVD incidence of $6.0 \%$ among medical students. These results are similar to another study by Praminik et al. conducted at Nepal Medical College, which reported that $5.8 \%$ of medical students were color weak [6]. The prevalence of CVD among junior medical students in the United States is reported to be higher at $12.8 \%$ while $7.8 \%$ is observed among dental students [9, 10]. In another study conducted in the United Kingdom, a higher CVD prevalence among histology students was reported at $8.7 \%$ [11]. In a study conducted by Sangeeta Kar et al. in Odisha, the prevalence of CVD was observed to be $8.9 \%$ [12]. These variable differences in CVD prevalence could be attributed to differences in study population, geographical variations, ethnicity, and color vision test techniques.

This study found no significant association $(p=0.070)$ between gender and the presence of color deficiency. Although the male: female ratio is markedly different in several published studies, multiple studies showed that CVD was only found among males [1315]. This could be explained by the X-linked recessive nature of the trait and thus occurs in males [16]. However, gender had no impact on CVD incidence in this study that could be attributed to the lack of differentiation between congenital and acquired cases causing overestimation in the prevalence of CVD among females resulting in a non-statistically significant difference between the two genders.

This study found a significant association between age $(p=0.001)$ and the incidence of CVD. It has been proven that the prevalence of CVD decreases until midlife and increases thereafter. A higher proportion (76.9\%) of those with CVD were aged $>20$ years in this study. This could be potentially explained by the increased exposure to environmental factors among those with older age which influences the acquired color deficiency [17-19].

Finally, this study demonstrated a significant association between socioeconomic status $(p=0.001)$ and color deficiency. Poor socioeconomic status has been previously reported to be associated with multiple visual abnormalities. More of the medical students (38.5\%) with color deficiency belonged to the poor socio-economic group in this study that could be potentially explained by the decreased levels of eye health awareness, poverty, and lack of affordability of proper health-care services for color deficiency screening $[20,21]$.

However, some limitations of this study must be considered. This study was conducted at a single tertiary care center in Pakistan. Another limitation is the lack of differentiation between acquired and congenital color deficiency. More studies at multiple primary care 
settings involving a larger sample size are needed to further potentiate the findings of the current study.

\section{Conclusions}

Color deficiency is demonstrated to be fairly common among medical students in this study. This study highlights the need to conduct continuous visual screening programs among medical students for early detection of CVD and awareness sessions should be provided so that they take special caution as future doctors in clinical practice.

\section{References}

1. Cumberland P, Rahi JS, Peckham CS: Impact of congenital colour vision defects on occupation. Arch Dis Child. 2005, 90:906-8. 10.1136/adc.2004.062067

2. Al-Aqtum MT, Al Qawasmeh MI-I: Prevalence of color blindness in young Jordanians. Ophthalmologica. 2001, 215:39-42. 10.1159/000050824

3. Spalding JA: Color vision deficiency in medical profession. Br J Gen Pract. 1999, 49:469-75.

4. Campbell JL, Griffin L, Spalding JAB, Mir FA: The effect of abnormal color vision on the ability to identify and outline colored clinical signs and to count stained bacilli in sputum. Clin Exp Optom. 2005, 88:376-81. 10.1111/j.14440938.2005.tb05103.x

5. Rubin LR, Lakey WL, Kennedy FA, Stephenson RB: Using color and grey scale images to teach histology to color- deficient medical students. Anat Sci Ed. 2009, 2:84-8. 10.1002/ase.72

6. Pramanik T, Sherpa MT. Shrestha R: Color vison deficieny among medical students: an unnoticed problem. Nepal Med Coll J. 2010, 12:81-3.

7. Siddiqui QA, Shaikh SA, Qureshi TZ, Subhan MM: A comparison of red-green colour vision deficiency between medical and non-medical students in Pakistan. Saudi Med J. 2010, 31:895-9.

8. Poole CJM, Hill DJ, Christie JL, Birch J: Deficient colour vision and interpretation of histopathology slides: cross sectional study. BMJ. 1997, 315:1279. 10.1136/bmj.315.7118.1279

9. Logan JS: The disability in so called red green blindness: an account based on many years of self observation. Ulster Med J. 1977, 46:41-5.

10. Davison SP, Mysilinski NR: Shade selection by color vision defective dental personnel. J Prosth Dent. 1990, 63:97-101. 10.1016/0022-3913(90)90276-I

11. Olson IA: The use of colour filters by students with congenital color defects in the learning of histology. Med Biol Illus. 1971, 21:52-3.

12. Kar SS, Agrawala M: A study on colour vision deficiency among medical students of Odisha. J. Evid. Based Med. Healthc. 2018, 5:806-

8. 10.18410/jebmh/2018/162

13. Niroula DR, Saha CG: The incidence of colour blindness among some school children of Pokhara, Western Nepal. Nepal Med Coll J. 2010, 12:48-50. 
14. Yasmin A, Janan N, Akhter R: Assessment of colour blindness and erythrocyte G6PD enzyme status among the school children of Dhaka City. J Bangladesh Soc Physiol. 2009, 4:64-70. 10.3329/ibsp.v4i2.4175

15. Shrestha RK, Joshi MR, Shakya S, Ghising R: Colour vision defects in school going children. JNMA J Nepal Med Assoc. 2010, 50:264-6.

16. Shah A, Hussain R, Fareed M, Afzal M: Prevalence of red-green colour vision defects among muslim males and females of Manipur, India. Iran J Public Health. 2013, 42:16-24.

17. Attarchi MS, Labbafinejad Y, Mohammadi S: Occupational exposure to different levels of mixed organic solvents and colour vision impairment. Neurotoxicol Teratol. 2010, 32:558-62. 10.1016/j.ntt.2010.05.003

18. Guest M, D'Este C, Attia J, et al.: Impairment of color vision in aircraft maintenance workers. Int Arch Occup Environ Health. 2011, 84:72333. 10.1007/s00420-010-0600-9

19. Willmann G, Ivanov IV, Fischer MD, Lahiri S, Pokharel RK, Werner A, Khurana TS: Effects on colour discrimination during long term exposure to high altitudes on Mt Everest . Br J Ophthalmol. 2010, 94:1393-7. 10.1136/bjo.2009.178491

20. Dandona R, Dandona L: Socioeconomic status and blindness. Br J Ophthalmol. 2001, 85:1484-8. 10.1136/bjo.85.12.1484

21. Katibeh M, Rajavi Z, Yaseri M, Hosseini S, Hosseini S, Akbarian S, Sehat M: Association of socio-economic status and visual impairment: a populationbased study in Iran. Arch Iran Med. 2017, 20:43-8. 